\title{
Enhancing Recovery after Stroke with Noradrenergic Pharmacotherapy: A New Frontier?
}

\author{
David J. Gladstone, Sandra E. Black
}

\begin{abstract}
Despite much progress in stroke prevention and acute intervention, recovery and rehabilitation have traditionally received relatively little scientific attention. There is now increasing interest in the development of stroke recovery drugs and innovative rehabilitation techniques to promote functional recovery after completed stroke. Experimental work over the past two decades indicates that pharmacologic intervention to enhance recovery may be possible in the subacute stage, days to weeks poststroke, after irreversible injury has occurred. This paper discusses the concept of "rehabilitation pharmacology" and reviews the growing literature from animal studies and pilot clinical trials on noradrenergic pharmacotherapy, a new experimental strategy in stroke rehabilitation. Amphetamine, a monoamine agonist that increases brain norepinephrine levels, is the most extensively studied drug shown to promote recovery of function in animal models of focal brain injury. Further research is needed to investigate the mechanisms and clinical efficacy of amphetamine and other novel therapeutic interventions on the recovery process.
\end{abstract}

RÉSUMÉ: Favoriser la récupération après un accident vasculaire cérébral par la pharmacothérapie noradrénergique: une nouvelle frontière? Malgré les progrès importants dans le domaine de la prévention des accidents vasculaires cérébraux (AVC) et dans leur traitement en phase aiguë, la récupération et la réhabilitation ont traditionnellement reçu relativement peu d'attention du monde scientifique. Il y a actuellement un regain d'intérêt dans le développement de médicaments pour favoriser la récupération après un AVC et des techniques innovatrices de réhabilitation pour promouvoir la récupération fonctionnelle après un AVC complété. Le travail expérimental au cours des deux dernières décennies indique que l'intervention pharmacologique pour favoriser la récupération peut être possible en phase subaiguë, dans les jours ou les semaines suivant un AVC, après une lésion irréversible. Cet article discute du concept de la "réhabilitation pharmacologique" et revoit une littérature de plus en plus abondante sur les études chez l'animal et les études cliniques pilotes de pharmacothérapie, une nouvelle stratégie expérimentale dans la réhabilitation après un AVC. L'amphétamine, un agoniste de la monoamine qui augmente les niveaux de norépinéphrine dans le cerveau, est le médicament le plus étudié pour lequel on a démontré une influence favorable sur la récupération fonctionnelle dans les modèles animaux de lésion cérébrale focale. Il faudra poursuivre les recherches pour investiguer les mécanismes et l'efficacité clinique de l'amphétamine et d'autres interventions thérapeutiques innovatrices dans le processus de récupération.

Can. J. Neurol. Sci. 2000; 27: 97-105

Stroke is the most common serious neurological disorder. The burden of stroke-related disability is enormous and expected to increase with our aging population. Despite much progress in the areas of prevention and acute intervention, there has not yet been major therapeutic advance in the neurorehabilitation of patients after an established stroke. However, evidence is accumulating that pharmacotherapy combined with rehabilitation in the subacute phase after stroke can influence recovery.

Experimental work over the past two decades indicates that brain catecholamines play an important role in recovery from brain injury and that late intervention to enhance recovery after stroke may be possible by augmenting central noradrenergic neurotransmission. Amphetamine, a monoamine agonist which

From the Division of Neurology, Sunnybrook and Women's College Health Sciences Centre, University of Toronto, Toronto, Ontario, Canada. RECEIVEDAUGUST 9, 1999. ACCEPTEDINFINALFORMFEBRUAR Y 1, 2000.

Reprint requests to: David Gladstone, Cognitive Neurology Unit, Sunnybrook and Women's College Health Sciences Centre, 2075 Bayview Avenue, Room A421, Toronto, Ontario, Canada M4N 3M5 
increases brain norepinephrine levels, is the most extensively studied drug that has been shown to promote functional recovery in animal models of focal brain injury. The potential value of amphetamine for influencing recovery in human stroke patients has not yet been established. Clinical trials are currently underway to evaluate the role of such therapy. This paper reviews the experimental literature and preliminary clinical studies of poststroke noradrenergic pharmacotherapy, a new experimental approach in stroke rehabilitation.

\section{STROKE MANAGEMENT IN PERSPECTIVE}

Traditionally, the focus of stroke management has centered on prevention. Primary prevention through risk factor modification has been credited with the significant reductions in the incidence and mortality of stroke in the 1980s and 1990s. Secondary prevention with antiplatelet and anticoagulant therapies and carotid endarterectomy has also reduced stroke risk in symptomatic patients. Newer antithrombotic agents as well as carotid angioplasty and stenting are emerging therapies for stroke prophylaxis. Presently, the momentum for acute stroke care is moving towards an emergency response to "brain attack". ${ }^{1}$ Acute interventions aim at reperfusion with intravenous or intra-arterial thrombolysis, and neuroprotective agents are under development in order to salvage ischemic neurons and limit infarct size. These promising advances in acute treatment are tempered by important limitations: the majority of stroke patients do not present to hospital within the first few hours of stroke to be eligible for thrombolytic or cytoprotective therapy; not all hospitals and physicians are equipped or trained to offer such treatments; and the risk of treatment-related adverse effects is a concern. Over one hundred neuroprotective agents have been studied (drugs that must be administered before or immediately after stroke), but to date none has proven clinically successful. ${ }^{1,2}$

Given that not all strokes can be prevented and that significant limitations exist in the use of acute stroke treatments currently available, there is a strong need to direct attention towards the newest frontier of stroke management: enhancing recovery of the stroke survivor. Current treatment after stroke often consists of supportive care, prevention of complications, and conventional physical, occupational, cognitive and speech rehabilitation programs. The beneficial effects of rehabilitation are becoming increasingly recognized as randomized trials demonstrate improved outcome in patients who receive organized stroke unit care, ${ }^{3}$ and improved functional recovery with increased intensity of rehabilitation. ${ }^{4,5}$ Specific pharmacologic treatments to further improve the natural history of recovery are, however, lacking. The ideal treatment would be an intervention that could improve clinically meaningful outcomes, be administered safely and easily to the majority of stroke patients without the constraints of a narrow therapeutic time window, be cost-effective and well-tolerated. There is now a growing interest in the development of stroke recovery drugs and innovative rehabilitation techniques. The term "rehabilitation pharmacology" has been popularized by Feeney to denote the strategy of combining rehabilitation procedures with specific drugs that act on the central nervous system to promote an even greater recovery following brain injury. Excellent reviews of this topic have recently been published by
Goldstein and others. ${ }^{6-9}$ This new experimental approach may represent a promising step towards helping our patients achieve a greater recovery after stroke.

\section{ANIMAL STUDiEs OF AMPHETAMINE}

Pioneering experimental studies by Feeney and co-workers investigated the hypothesis that modulation of brain catecholamines may influence recovery after brain injury. In 1982, they published their observations in Science that amphetamine accelerated motor recovery in an animal model of hemiplegia. ${ }^{10}$ In these experiments, motor performance was assessed on a beam-walking task after unilateral ablation of sensorimotor cortex in the rat. Without treatment, rats were initially unable to walk across a narrow elevated beam, but their motor function eventually recovered by two weeks. Treatment with a single dose of amphetamine administered 24 hours after motor cortex ablation, however, significantly improved the rats' locomotion. By 24 hours the improvement was similar to that achieved by the control animals after one to two weeks, and this enhanced recovery persisted during the four weeks of the study. If the rats were restrained in a cage and prevented from walking for eight hours after drug administration, there was no improvement in rate of recovery. This observation suggested that amphetamine was effective only when given in conjunction with locomotor practice or "symptom-relevant experience" during the period of drug action. Moreover, they demonstrated that administration of a single dose of haloperidol slowed motor recovery when given alone, and blocked the amphetamineinduced acceleration of recovery when given together with amphetamine.

The acceleration of motor recovery after administration of amphetamine has been replicated in many other studies in rats $^{11-18}$ and in cats. ${ }^{19-21}$ In cats, Hovda and Feeney showed that even when amphetamine was given ten days after motor cortex ablation, beam-walking ability recovered more rapidly and more completely compared to control animals. ${ }^{19}$ In this study, cats were randomized to four groups and followed for 60 days. The placebo group had a slow and incomplete motor recovery at 60 days. Cats receiving a single dose of amphetamine ten days after motor cortex injury showed a significant improvement in motor recovery, beginning six hours after treatment and continuing for the 60-day duration of the study. Cats randomized to receive multiple doses of amphetamine (on days 10, 14, 18, 22) showed a dose-response effect with faster recovery compared to the single-dose group, and reached complete recovery by day 24 . These three groups all received beam-walking experience one, two, three, and six hours postinjection. In the fourth experimental group, cats that received multiple doses of amphetamine were not allowed symptom-relevant experience during amphetamine intoxication; this intervention initially slowed the rate of recovery but did not affect the ultimate level of recovery in this study.

Similar findings have been observed in animal experiments investigating different types of brain injury, recovery of other functions (in addition to motor recovery) and different treatment regimens. In a carotid artery territory embolic stroke model in rats, amphetamine administration for seven days beginning 24 hours poststroke resulted in significant improvement in 
locomotion compared to controls, and this improvement persisted beyond the period of drug action to the end of the experiment at 30 days poststroke. ${ }^{22}$ In another study involving carotid-territory infarction in rats, amphetamine or placebo was administered every third day for one month. ${ }^{23}$ The amphetaminetreated animals again showed not only greater recovery in the short-term, but also persistence of this recovery when retested at one month after completion of the treatment period (two months poststroke). Recovery of function following unilateral infarction of primary somatosensory cortex has also been studied. ${ }^{24,25}$ Amphetamine or saline was injected on days four, six, nine, and 11 poststroke, and rats were tested on a maze task requiring sensory-motor integration. ${ }^{24}$ Both groups had a similar initial performance deficit following infarction. The saline group gradually improved to within $10 \%$ of its baseline performance level between 25-35 days following infarction. The amphetamine-treated rats recovered at a faster rate, and a doseresponse effect was observed with the $4 \mathrm{mg} / \mathrm{kg}$ dose amphetamine group recovering faster (to within $10 \%$ of baseline by day 19) than the $2 \mathrm{mg} / \mathrm{kg}$ dose group. At the end of the study, day 35 , the amphetamine-treated rats had achieved a more complete recovery than the placebo group.

Feeney and Hovda examined recovery of binocular depth perception in cats after bilateral ablation of primary visual cortex. ${ }^{26}$ Depth perception, measured by performance on a visual cliff, is normally lost permanently after visual cortex ablation in cats despite some recovery of visual acuity. In this study, cats were randomized to three groups postsurgery and there were no differences in the lesion size between groups. The treatment group received amphetamine $(5 \mathrm{mg} / \mathrm{kg})$ on days $10,14,18$ and 22 post surgery, with visual cliff testing at one, two three and six hours post drug administration on each drug day. After the first treatment, these cats showed a significant improvement and by four days after the last dose they had recovered completely. This recovery persisted over the 42 days of observation after stopping drug treatment. The control animals were given the same experience on the visual cliff but received saline treatments, and showed no recovery of binocular depth perception. A final group of cats was given seven doses of amphetamine $(5 \mathrm{mg} / \mathrm{kg})$ on days $10,14,18,22,26,30,45$, but housed in total darkness for 24 hours after each drug administration and not tested during these periods. This "visual deprivation" group also showed no recovery of depth perception. Like many of the studies of motor recovery, this study of visual recovery again suggests that provision of "symptom-relevant experience" in combination with amphetamine treatment is necessary for promotion of recovery. The lack of recovery observed in those animals housed in the dark (but receiving amphetamine) is evidence against a simple psychostimulant effect as an explanation for these findings. Additionally, amphetamine-induced restoration of depth perception is blocked by haloperidol. ${ }^{27}$ A subsequent study replicated these findings although some amphetamine-treated cats recovered only transiently and some showed no improvement. ${ }^{28}$ Administration of amphetamine one to eight months after visual cortex ablation, ${ }^{29}$ or more than three months postinjury, ${ }^{26}$ provided no improvement, suggesting a therapeutic window may exist after which amphetamine plus symptomrelevant experience does not promote recovery.

In contrast to the beneficial effects of amphetamine for recovery from focal cortical lesions, there is evidence that amphetamine may have detrimental effects when given to animals with infratentorial lesions affecting the cerebellum ${ }^{30}$ or substantia nigra. ${ }^{31}$

In summary, several experimental animal studies have demonstrated consistent findings: amphetamine plus experience can accelerate spontaneous recovery after cortical injury and can even produce a higher level of recovery than would normally occur. A dose-response relationship has been identified in the shape of an inverted $U$, with higher doses producing a decremental response. ${ }^{32}$ Repeated drug administrations facilitate recovery significantly better than a single treatment. Maximum improvement appears when amphetamine and related drugs are combined with task-specific practice following drug administration, emphasizing the importance of an interaction between drug action and symptom-relevant experience. ${ }^{13,14}$

\section{THE NORADRENERGIC HYPOTHESIS}

While administration of amphetamine increases central norepinephrine, dopamine, and serotonin, the underlying neurochemical basis for amphetamine-enhanced recovery of function is postulated to be an increase in central noradrenergic activity.

Following cortical injury, there is a reduction of norepinephrine and other monoamines in the brain as well as a reduction of alpha-1 noradrenergic receptors without upregulation of norepinephrine release. ${ }^{33-44} \mathrm{~A}$ reduction in norepinephrine concentration persists in the ipsilateral cortex and brainstem 40 days postinfarction in the rat, whereas dopamine concentrations remain decreased in the brainstem but not in the cortex. ${ }^{35}$

The importance of norepinephrine in recovery is supported by studies showing that drugs which enhance central noradrenergic transmission enhance functional recovery. For example, direct intraventricular infusion of norepinephrine promotes hemiplegia recovery in the rat. ${ }^{45}$ In contrast, enhancing dopaminergic activity (with the dopamine agonist apomorphine, levodopa, or intraventricular infusion of dopamine), or enhancing serotonergic activity (with fluoxetine or intraventricular infusion of serotonin) have no effect on recovery in the rat hemiplegia model. ${ }^{46,47}$ The centrally-acting alpha-2 (presynaptic) adrenergic receptor antagonists, yohimbine and idazoxan, both increase norepinephrine release; these agents, like amphetamine, facilitate motor recovery when given as a single dose after unilateral sensorimotor cortex injury. ${ }^{16,17,48,49}$ The amphetamine analogues, phentermine, phenylpropanolamine and methylphenidate also accelerate motor recovery after focal brain injury. ${ }^{50-52}$ Acceleration of recovery is felt to be independent of the psychostimulant properties of amphetamine, which are mediated by dopamine. Desipramine, which does not have stimulant effects, blocks reuptake of norepinephrine and facilitates recovery from hemiplegia in the rat. ${ }^{53}$

Converging evidence for the noradrenergic hypothesis comes from studies of drugs which reduce central noradrenergic activity. Selective depletion of central norepinephrine with the neurotoxin DSP-4 (N-(2-chloroethyl)-N-ethyl-2-bromobenzylamine) is associated with significantly slowed beam-walking recovery in rats with unilateral sensorimotor cortex lesions and, 
on pathological examination, the recovery correlates inversely with norepinephrine content. ${ }^{54,55}$ Blockade of alpha-1 noradrenergic receptors or activation of negative feedback with alpha-2 noradrenergic agonists has also been shown to slow functional recovery. Moreover, administration of these drugs to recovered rats or cats will temporarily reinstate the deficit. A single dose of the alpha-2 adrenergic receptor agonist clonidine administered to rats 24 hours after unilateral sensorimotor cortex ablation significantly slows the rate of beam walking recovery and the impairment persists for at least five days after treatment. ${ }^{56}$ Administration of clonidine to rats that have recovered results in a transient reinstatement of motor deficit in a dose-related fashion. ${ }^{57}$ Similarly, administration of the alpha-1 noradrenergic receptor antagonist prazosin one month after injury reinstates the hemiplegia, whereas the same treatment has no effect on normal control animals. ${ }^{16}$ It has been emphasized that such reinstatement of motor deficit cannot be due to a nonspecific sedative drug effect since the deficits appear only in the limbs contralateral to the cortical injury and a sedating dose of barbiturates does not reinstate the hemiplegia. The finding that haloperidol impairs beam-walking recovery in rats with sensorimotor cortex lesions has been attributed to its ability to block postsynaptic alpha-1 noradrenergic receptors. ${ }^{10,58}$ Other animal studies have demonstrated similar slowing of recovery and reinstatement of deficits by norepinephrine blockade. ${ }^{59}$

Taken together, pharmacological studies suggest that norepinephrine plays an important role in mediating some forms of recovery following focal cortical injury, and that the recovery process is vulnerable to change with modulation of norepinephrine transmission. An increase in central norepinephrine is the postulated pharmacologic basis by which amphetamine facilitates recovery. These observations have direct clinical implications concerning the potential for drugs to exert beneficial or harmful effects in human stroke patients.

\section{Clinical STUdies OF STROKE RECOVERY IN HUMANS}

\section{Pilot studies of amphetamine}

Preliminary studies have been conducted in small groups of patients to determine if the results from animal studies can be replicated in humans. Although far from conclusive, these pilot studies do suggest that amphetamine may hold promise in the rehabilitation of motor and language deficits following stroke.

In 1988, Crisostomo et al published a prospective doubleblind randomized controlled trial of eight hemiplegic stroke patients investigating the effect on motor recovery of a single dose of amphetamine paired with physiotherapy. ${ }^{60}$ Patients were randomized three to ten days poststroke to receive either a single low dose of amphetamine $(10 \mathrm{mg})$ or placebo, combined with a physiotherapy session within three hours. The outcome measure was the Fugl-Meyer score (a validated and reliable motor scale) rated by a blinded physiotherapist. After one day, they noted an enhanced motor improvement. The treatment group showed significantly greater improvement in motor scores from their pretreatment baseline scores (14 points in two of the four treated patients), compared to the placebo group (maximum 2-point improvement).

Another study was reported by Reding et al only in abstract form. ${ }^{61,62}$ This randomized controlled trial investigated the effect of a different treatment regimen: amphetamine given daily for 17 days during inpatient stroke rehabilitation. Patients were enrolled more than one month poststroke and randomized to receive either placebo $(n=12)$ or $10 \mathrm{mg}$ amphetamine daily for 14 days followed by $5 \mathrm{mg}$ daily for three days $(\mathrm{n}=9)$. Outcome measures were the Fugl-Meyer, Barthel, and Zung depression scales. This study did not detect a difference between the groups, and a variety of explanations have been suggested to account for the negative study: treatment was initiated after one month poststroke which may be too late (beyond the potential therapeutic window); the dosing regimen utilized continuous daily dosing which, theoretically, may lead to neurotransmitter depletion; and implementation of physiotherapy was not standardized to occur in conjunction with drug administration.

The most convincing data to date come from Walker-Batson et al in 1995.63 They conducted a randomized controlled trial of ten ischemic hemispheric stroke patients with moderately-severe or severe hemiplegia (rated as Fugl-Meyer score $<55$ at baseline). Applying principles derived from animal studies, they randomized patients 16-30 days poststroke to receive either ten doses of amphetamine, each followed by physiotherapy (amphetamine $(10 \mathrm{mg})$ paired with physiotherapy every four days for ten sessions) or ten doses of placebo followed by physiotherapy. Importantly, there were no baseline differences in motor scores between the groups and both groups were randomized at an average of 22 days poststroke. Outcome measure was the Fugl-Meyer score at each session, one week afterwards, and again at three, six, and 12 months poststroke. They reported significantly greater motor recovery in the amphetamine group compared to the control group, beginning by the second treatment session and continuing up to one year poststroke (ten months after treatment stopped). They concluded that amphetamine paired with physiotherapy accelerated the rate and increased the final level of motor recovery. This study had a very small number of patients but a good trial design, long follow-up period, and a standardized protocol for treatment sessions and drug dosing was established. The study investigators were not blinded but the patients and physiotherapists involved in the rehabilitation and motor assessments were blinded.

Pharmacotherapy for aphasia with amphetamine has also been explored by Walker-Batson et al with preliminary results that are encouraging. ${ }^{64-67}$ They reported on 11 patients with various types of aphasia from dominant hemisphere ischemic stroke who received amphetamine treatments $(10 \mathrm{mg}$ followed 30 minutes later by a one-hour standardized speech/language therapy protocol). ${ }^{64}$ The first treatment began within 30 days poststroke, and continued every fourth day for a total of ten treatment sessions. There was no control group. Language function was rated on the Porch Index of Communicative Abilities (PICA) and compared to a six-month predicted outcome score calculated for each patient based on their baseline performance scores. At six months, language recovery for patients treated with amphetamine exceeded the recovery expected without any intervention, with a mean improvement of ten points on the PICA scale. Accelerated recovery occurred in eight of the 11 patients and was evident at one week after drug therapy stopped. Unfortunately, the number of patients studied here was again small and, importantly, there was no comparison 
to a placebo control group. Furthermore, the potential for bias is strong in rating patients without blinding.

The use of low-dose $(10 \mathrm{mg})$ amphetamine has not been associated with side effects in any of these clinical studies, specifically no adverse effects on heart rate or blood pressure. ${ }^{68}$ Walker-Batson's group documented in 26 amphetamine-treated stroke patients that amphetamine did not increase systolic or diastolic blood pressure. Patients with uncontrolled hypertension of $160 / 100 \mathrm{mmHg}$ or more were excluded from entry into the study. ${ }^{69}$ Insomnia occurred in one patient who received a higher dose $(15 \mathrm{mg})$ of amphetamine. ${ }^{64}$

In addition to amphetamine, methylphenidate has recently been tried in a similar fashion in a small, randomized, controlled trial of poststroke rehabilitation. ${ }^{70}$ Twenty-one stroke patients were randomized at day 18 poststroke to receive methylphenidate or placebo plus physiotherapy for up to three weeks. The authors reported a beneficial effect for methylphenidate on depression scores, motor function and functional independence. Efficacy is difficult to ascertain in this small study as this was a heterogeneous sample of stroke patients, many patients had high initial motor scores and drug doses and follow-up were variable. This study, like those of amphetamine, does suggest that the strategy of poststroke rehabilitation pharmacology is safe and feasible.

\section{Studies of adverse effects of drugs on stroke recovery}

Just as amphetamine appears to have beneficial effects on recovery, there has been increasing interest in elucidating which medications may have harmful effects on the recovery process in humans. As mentioned earlier, a number of drugs have been shown to impair recovery after focal brain injury in animals. Goldstein has drawn attention to the fact that many of the drugs which have detrimental effects in animals are commonly prescribed to hospitalized patients after stroke ${ }^{71}$ and head injury $^{72}$ and may have similar detrimental effects on recovery in humans.,73,74 These drugs include the antihypertensives clonidine and prazosin, haloperidol and other dopamine antagonists, benzodiazepines, phenytoin and phenobarbital. There is evidence now from retrospective studies of stroke patients that exposure to such potentially detrimental drugs is associated with poorer motor recovery, independent of the severity of initial deficit or comorbid conditions. ${ }^{75-77}$ Future studies may better define specific medications which might be contraindicated in the poststroke period.

\section{THEORIES OF RECOVERY}

The mechanisms by which amphetamine and related drugs affect recovery are not known. Multiple hypotheses have been proposed for how noradrenergic drugs might affect the recovery process. ${ }^{32,78,79}$ Theories to explain amphetamine-facilitated recovery must take into account the following observations: functional improvement can begin rapidly (within hours) after drug administration; short-term administration of drug produces sustained improvement in behavioral recovery that persists well beyond the period of the drug's pharmacological action, suggesting permanent physiological changes take place; and behaviorally-relevant training appears necessary in interaction with the drug to produce the desired effect.

Resolution of diaschisis has been entertained as a potential mechanism for brain recovery after stroke. ${ }^{80}$ Diaschisis, a term introduced by von Monakow in 1914, refers to the concept that damage in one particular brain region may produce not only local effects, but also effects in brain areas distant from but functionally connected to the primary lesion. ${ }^{81}$ Such remote effects can be detected as regions of reduced cerebral metabolism or perfusion on functional neuroimaging studies, and are felt to represent dysfunctional but morphologically intact neurons. ${ }^{80}$ Several patterns have been described, including crossed cerebellar diaschisis, cerebello-cortical diaschisis, transhemispheric diaschisis, basal ganglia-cortical diaschisis, thalamo-cortical diaschisis, and cortico-thalamic diaschisis. ${ }^{82}$ Feeney postulates that alleviation of diaschisis may play a role in amphetamine-induced recovery. ${ }^{83,84}$ Infusions of norepinephrine into the contralateral but not ipsilateral cerebellar hemisphere enhanced beam walking recovery in the rat model of hemiplegia. ${ }^{85}$ If diaschisis truly contributes to the clinical deficit after stroke, then attempts to alleviate diaschisis with pharmacotherapy make good sense. However, the clinical significance of diaschisis, its contribution to symptoms and its role in recovery remain controversial and have been subject to debate. $^{82,86}$

Noradrenergic pharmacotherapy with rehabilitation may lead to an enhanced functional recovery by augmenting natural processes of brain plasticity. Modern concepts of stroke recovery implicate the brain's capacity to undergo dynamic, plastic change. ${ }^{87,88}$ Natural history studies show that most stroke patients experience some degree of spontaneous improvement, especially during the first three months poststroke, and this recovery may in part reflect innate processes of remodeling and repair. Potential mechanisms include "unmasking" of latent connections, "redundancy" allowing recruitment of alternate parallel pathways to take over lost functions, and axonal "sprouting" from surviving neurons with formation of new synapses. ${ }^{89}$ Involvement of the ipsilateral hemisphere in recovery has been implicated as well, as exemplified by motor recovery in patients who have undergone hemispherectomy. Functional neuroimaging studies of patients after stroke demonstrate clear changes in cerebral activation patterns accompanying recovery of function-activations in the ipsilateral (non-infarcted) cerebral hemisphere, in peri-infarct regions and in additional cortical areas within the affected hemisphere. These changes are interpreted by many to represent reorganization of the injured brain. ${ }^{90-94}$

Increasing experimental evidence suggests that cortical plasticity, which may underlie spontaneous recovery from stroke, can be modulated by both rehabilitative training and pharmacological therapy. ${ }^{88,95,96}$ For example, using intracortical microstimulation techniques in monkeys, Nudo et al have shown that following a small focal injury in the hand motor cortical region, there is a loss of hand representation in the surrounding intact cortex; ${ }^{97}$ with rehabilitative training, there is maintenance or expansion of hand representation in adjacent cortex. ${ }^{95}$ It is speculated that such activity-dependent cortical changes can be even further facilitated when combined with appropriate pharmacologic modulation during a critical postinjury period. ${ }^{98}$ However, caution must be exercised as Schallert et al showed that forced overuse of a paretic limb in the early recovery period in rats can be detrimental and increase infarct size. ${ }^{99}$ Elegant 
immunohistochemical studies by Stroemer et al provide strong evidence for enhanced neuroplasticity as a mechanism for the behavioral recovery induced by amphetamine and physical therapy in rats following cortical infarction. ${ }^{96,100}$ They documented that amphetamine treatment (compared to saline) led to increased expression of proteins that reflect neural sprouting and synaptogenesis in the peri-infarct cortex, as well as in the ipsilateral cortex, and these trophic changes correlated with the observed improvement in behavioural recovery. They proposed that amphetamine promotes neuronal remodeling by activation of alternate neural pathways stimulated by behavioural use. Similar results have also been demonstrated following intracisternal injection of neurotrophic growth factors. ${ }^{101,102}$ There is evidence that norepinephrine increases cerebral metabolism following cortical injury. ${ }^{83,103}$ In this way, amphetamine might help activate alternate neural pathways in surrounding brain regions to take over lost functions. The concept of long-term potentiation, a putative cellular mechanism of learning and memory, has been invoked to account for enduring improvement following short-term drug administration. Norepinephrine and amphetamine have been shown to facilitate the development of long-term potentiation, whereas clonidine and neuroleptics block long-term potentiation. ${ }^{32,104}$ Perhaps recovery involves relearning which can be facilitated pharmacologically when amphetamine is added to rehabilitation training. Future studies might explore the influence of such pharmacological interventions on poststroke neurogenesis and on functional gains following neural stem cell transplantation.

In humans, emerging data suggest that amphetamine can enhance use-dependent plasticity in the motor cortex. In an experimental paradigm of use-dependent plasticity employing transcranial magnetic stimulation, cortical thumb representation was altered by repetitive training in healthy volunteers. ${ }^{105} \mathrm{~A}$ single dose of amphetamine (10 mg) enhanced the development of this use-dependent plasticity. ${ }^{106}$ Furthermore, neuroimaging studies are beginning to show that amphetamine administration may influence brain activity in a way that is measurable with positron emission tomography (PET) and functional magnetic resonance imaging (fMRI) and may lead to a more focused activation or enhancement of the specific neural systems involved in a given task. ${ }^{107,108} \mathrm{~A}$ recent fMRI study of healthy subjects reported that amphetamine $(20 \mathrm{mg})$ increased the volume of brain activation during finger tapping tasks. ${ }^{109}$

\section{Conclusions}

Until recently, stroke management has focused on prevention and acute intervention, with little attention devoted to the recovery of patients after completed stroke. The potential for enhancing recovery with pharmacotherapy days to weeks poststroke, after irreversible brain injury has occurred, is an exciting new frontier in stroke management. Experimental studies have shown the importance of central noradrenergic transmission in mediating some forms of recovery following focal cortical injury. Increasing evidence suggests that pharmacotherapy to increase noradrenergic activity (short-term treatment with low-dose amphetamine), in combination with rehabilitation in the subacute phase after stroke, can promote an enduring enhancement of functional recovery.
The evidence to date is compelling and demands that amphetamine therapy be subjected to proper study in randomized controlled clinical trials. Until then, the use of amphetamine for stroke recovery must still be considered experimental. In order to demonstrate efficacy of any stroke recovery therapy, it must be shown that the intervention is better than the natural history of recovery. It is critical then, that the design of such studies aims to choose sensitive outcome measures that can detect meaningful change, and minimize variability in rate and degree of spontaneous recovery by investigating large samples of patients homogeneous with respect to severity of neurologic impairment, lesion size and location. There may be differential drug effects depending on whether the right or left hemisphere is affected ${ }^{36}$ and whether the lesion is cortical or subcortical. A variety of behavioural outcomes should be examined including motor, somatosensory, and visual recovery, as well as recovery from aphasia and neglect. Future clinical studies might also investigate recovery following intracerebral hemorrhage and traumatic brain injury. The optimal therapeutic window, timing of intervention, medication dose, dosing schedule, rehabilitation technique, and intensity of training, are issues which need to be addressed by well-designed trials. While much remains to be learned about the mechanisms of amphetamine-induced behavioural recovery, it is possible that amphetamine acts to facilitate adaptive usedependent cortical plasticity.

The challenge for the next decade of neuroscience research will be to better understand the complex mechanisms of brain plasticity and to develop rational therapies aimed at promoting recovery based on scientific understanding of these processes. We are now in the era of new, noninvasive functional brain mapping techniques such as functional magnetic resonance imaging, transcranial magnetic stimulation and evoked potentials, and are becoming capable of studying the injured brain as it recovers. With these tools it should be possible to track the recovery process in individual stroke patients and to study the effects of therapeutic interventions on human brain recovery in vivo.

\section{ACKNOWLEDGEMENTS}

The authors gratefully acknowledge the support of the Royal College of Physicians and Surgeons of Canada/University of Toronto Department of Medicine Clinician-Scientist Program.

\section{REFERENCES}

1. Hill MD, Hachinski V. Stroke treatment: time is brain. Lancet 1998;352:10-14.

2. Hachinski V. Relevance of rodent models of stroke. Arch Neurol 1996;53:1070.

3. Stroke Unit Trialists. Organised inpatient (stroke unit) care for stroke. The Cochrane Library, 1999.

4. Kwakkel G, Wagenaar RC, Koelman TW, Lankhorst GJ, Koetsier JC. Effects of intensity of rehabilitation after stroke: a research synthesis. Stroke 1997;28:1550-1556.

5. Kwakkel G, Wagenaar RC, Twisk JWR, Lankhorst GJ, Koetsier JC. Intensity of leg and arm training after primary middle-cerebralartery stroke: A randomized trial. Lancet 1999;354:191-196.

6. Goldstein LB. Restorative neurology: Advances in Pharmacotherapy for Recovery After Stroke. New York: Futura Publishing, 1998.

7. Goldstein LB. Pharmacologic effects on recovery of neurologic function. In: Lazar RB, ed. Principles of Neurologic Rehabilitation. New York: McGraw Hill, 1998:565-578. 
8. Feeney DM. Rehabilitation pharmacology: noradrenergic enhancement of physical therapy. In: Ginsberg MD, Bogousslavsky J, eds. Cerebrovascular Disease. Blackwell Science, 1998:620-636.

9. Geldmacher DS. Enhancing recovery from ischemic stroke. Neurosurg Clin N Am 1997;2:245-251.

10. Feeney DM, Gonzalez A, Law WA. Amphetamine, haloperidol, and experience interact to affect rate of recovery after motor cortex injury. Science 1982;217:855-857.

11. Feeney DM. Amphetamine restores locomotor function after motor cortex injury in the rat. Proc West Pharmacol Soc 1981;24:15-17.

12. Dunbar GL, Smith GA, Look SK, Whalen RJ. $\delta$-amphetamine attenuates learning and motor deficits following cortical injury in rats. Soc Neurosci Abstr 1989;15:132 (Abstract).

13. Goldstein LB, Davis VA. The role of experience on amphetaminefacilitated recovery of beam-walking in the rat. Soc Neurosci Abstr 1989;15:69(Abstract).

14. Goldstein LB, Davis JN. postlesion practice and amphetaminefacilitated recovery of beam-walking in the rat. Restor Neurol Neurosci 1990;2:311-314.

15. Goldstein LB. Amphetamine-facilitated functional recovery after stroke. In: Ginsberg MD, Dietrich WD, eds. Cerebrovascular Diseases. New York: Raven Press, 1989:303-308.

16. Sutton RL, Feeney DM. $\alpha$-noradrenergic agonists and antagonists affect recovery and maintenance of beam-walking ability after sensorimotor cortex ablation in the rat. Restor Neurol Neurosci 1992:4:1-11.

17. Irish SL, Davis GW, Barth TM. A specific behavioral role for norepinephrine in the recovery of locomotor placing following cortical lesions in the rat. Soc Neurosci Abstr 1995;21:170 (Abstract).

18. Goldstein LB. The influence of lesion size and location on amphetamine facilitated recovery of beam walking in rats. Behav Neurosci 1990;104:320-327.

19. Hovda DA, Fenney DM. Amphetamine with experience promotes recovery of locomotor function after unilateral frontal cortex injury in the cat. Brain Res 1984;298:358-361.

20. Feeney DM. Amphetamine and apomorphine restore tactile placing after motor cortex injury in the cat. Psychopharmacology 1983;79:67-71.

21. Sutton RL, Hovda DA, Feeney DM. Amphetamine accelerates recovery of locomotor function following bilateral frontal cortex ablation in cats. Behav Neurosci 1989;103:837-841.

22. Salo AA, Feeney DM. Reduction of morbidity, mortality, and lesion size in a rat model of cerebral infarction with amphetamine. Soc Neurosci Abstr 1987;13:1268(Abstract)

23. Stroemer RP, Kent TA, Hulsebosch CE. Amphetamines permanently promote recovery following cortical infarction. Soc Neurosci Abstr 1994;20:186(Abstract).

24. Hurwitz BE, Dietrich WD, McCabe PM, et al. Amphetamine promotes recovery from sensory-motor integration deficit after thrombotic infarction of the primary somatosensory rat cortex. Stroke 1991;22:648-654.

25. Dietrich WD, Alonso O, Busto R, et al. Influence of amphetamine treatment on somatosensory function of the normal and infarcted rat brain. Stroke 1990;21:147-150.

26. Feeney DM, Hovda DA. Reinstatement of binocular depth perception by amphetamine and visual experience after visual cortex ablation. Brain Res 1985;342:352-356.

27. Hovda DA, Feeney DM. Haloperidol blocks amphetamine-induced recovery of binocular depth perception after bilateral visual cortex ablation in cats. Proc West Pharmacol Soc 1985;28:209211.

28. Hovda DA, Sutton RL, Feeney DM. Amphetamine-induced recovery of visual cliff performance after bilateral visual cortex ablation in cats: measurement of depth perception thresholds. Behav Neurosci 1989;103:574-584.

29. Cornwell P. Performance on the visual cliff by cats with marginal gyrus lesions. Physiol Psychol 1976;90:996-1010.

30. Boyeson MG, Feeney DM. Adverse effects of catecholaminergic agonists and antagonists on recovery of locomotor ability following unilateral cerebellar ablations. Restor Neurol Neurosci
1991;3:227-233.

31. Mintz M, Tomer R. Exposure to amphetamine after substantia nigra lesion interferes with the process of behavioral recovery. Pharmacol Biochem Behav 1986;25:1307-1311.

32. Goldstein LB. Pharmacology of recovery after stroke. Stroke 1990;21(suppl III):III-139--III-142.

33. Prasad MR, Ramaiah C, McIntosh TR, et al. Regional levels of lactate and norepinephrine after experimental brain injury. J Neurochem 1994;63:1086-1094.

34. Dunn-Meynell A, Pan S, Levin BE. Focal traumatic brain injury causes widespread reductions in rat brain norepinephrine turnover from 6 to $24 \mathrm{hr}$. Brain Res 1994;660:88-95.

35. Robinson RG, Shoemaker WJ, Schlumpf M, Coyle JT. Effect of experimental cerebral infarction in rat brain on catecholamines and behavior. Nature 1975;255:332-334.

36. Robinson RG. Differential behavioral and biochemical effects of right and left hemispheric cerebral infarction in the rat. Science 1979;205:707-710.

37. Finklestein S, Campbell A, Baldessarini RJ, Moya K, Haber SN. Late changes in cerebral monoamine metabolism following focal ventrolateral cerebrocortical lesions. Brain Res 1985;344:205210.

38. Boyeson MG, Feeney DM. Striatal dopamine after cortical injury. Exp Neurol 1985;89:479-483.

39. Meyer JS, Stoica E, Pascu I, Shimazu K, Hartmann A. Catecholamine concentrations in CSF and plasma of patients with cerbral infarction and hemorrhage. Brain 1973;96:277-288.

40. Brown RM, Carlson A, Ljungren BL, Seisjo BK, Snider SR. Effect of ischemia on monoamine metabolism in the brain. Acta Physiol Scand 1974:90:789-791.

41. Cohen HP, Woltz AG, Jacobson RL. Catecholamine content of cerebral tissue after occlusion or manipulation of middle cerebral artery in cats. J Neurosurg 1975;43:32-36.

42. Prasad MR, Tzigaret CM, Smith D, Soares H, McIntosh TK. Decreased alpha 1-adrenergic receptors after experimental brain injury. J Neurotrauma 1992;9:269-279.

43. Levin BE, Pan S, Dunn-Meynell A. Chronic alterations in rat brain alpha-adrenoreceptors following traumatic brain injury. Restor Neurol Neurosci 1994;7:5-12.

44. Robinson RG, Shoemaker WJ, Schlumpf M. Time course of changes in catecholamines following right hemisphere cerebral infarction in the rat. Brain Res 1980;181:202-208.

45. Boyeson MG, Feeney DM. Intraventricular norepinephrine facilitates motor recovery following sensorimotor cortex injury. Pharm Biochem Behav 1990;35:497-501.

46. Feeney DM, Weisend MP, Kline AE. Noradrenergic pharmacotherapy, intracerebral infusion and adrenal transplantation promote functional recovery after cortical damage. J Neurotransplantation 1994;4:199-214.

47. Boyeson MG, Harmon RL, Jones JL. Comparative effects of fluoxetine, amitriptyline and serotonin on functional motor recovery after sensorimotor cortex injury. Am J Phys Med Rehabil 1994;73:76-83

48. Goldstein LB, Poe HV, Davis JN. An animal model of recovery of function after stroke: Facilitation of recovery by an $\mathrm{a}_{2}$-Adrenergic receptor antagonist. Ann Neurol 1989;26:157 (Abstract).

49. Feeney DM, Sutton RL. Catecholamines and recovery of function after brain damage. In: Sabel BA, Stein DG, eds. Pharmacological Approaches to the Treatment of Brain and Spinal Cord Injury. New York: Plenum, 1988:121-142.

50. Hovda DA. Phentermine accelerates recovery of function after motor cortex injury in rats and cats. FASEB J 1983;42:1157.

51. Kline AE, Chen MJ, Tso-Olivas DY, Feeney DM. Methylphenidate treatment following ablation-induced hemiplegia in rat: Experience during drug action alters effects on recovery of function Pharm Biochem Behav 1994; 48:773-779.

52. Chen MJ, Sutton RL, Feeney DM. Recovery of function following brain injury in rat and cat: Beneficial effects of phenylpropanolamine. Soc Neurosci Abstr 1986;12:881 (Abstract).

53. Boyeson MG, Harmon RL. Effects of trazadone and desipramine on motor recovery in brain-injured rats. Am J Phys Med Rehabil 1993;72:286-293. 
54. Goldstein LB, Coviello A, Miller GD, Davis JN. Norepinephrine depletion impairs motor recovery following sensorimotor cortex injury in the rat. Restore Neurol Neurosci 1991;3:41-47.

55. Boyeson MG, Callister TR, Cavazos JE. Biochemical and behavioral effects of a sensorimotor cortex injury in rats pretreated with the noradrenergic neurotoxin DSP-4. Behav Neurosci 1992;106:964-973.

56. Goldstein LB, Davis JN. Clonidine impairs recovery of beamwalking after a sensorimotor cortex lesion in the rat. Brain Res 1990;508:305-309.

57. Stephens J, Goldberg G, Demopoulos JT. Clonidine reinstates deficits following recovery from sensorimotor cortex lesion in rats. Arch Phys Med Rehabil 1986;67:666-667 (Abstract).

58. Feeney DM, Westerberg VS. Norepinephrine and brain damage: alpha noradrenergic pharmacology alters functional recovery after cortical trauma. Can J Psychol 1990;44:233-252.

59. Hovda DA, Feeney DM, Salo AA, Boyeson MG. Phenoxybenzamine but not haloperidol reinstates all motor and sensory deficits in cats fully recovered from sensorimotor cortex ablations. Soc Neurosci Abstr 1983;9:1002 (Abstract).

60. Crisostomo EA, Duncan PW, Propst M, Dawson DV, Davis JN. Evidence that amphetamine with physical therapy promotes recovery of motor function in stroke patients. Ann Neurol 1988;23:94-97.

61. Reding M, Solomon B, Borucki SJ. Effect of dextroamphetamine on motor recovery after stroke. Neurology 1995;45:A222(Abstract).

62. Borucki SJ, Langberg J, Reding M. The effect of dextroamphetamine on motor recovery after stroke. Neurology 1992;42:329 (Abstract).

63. Walker-Batson D, Smith $\mathrm{P}$, Curtis S, Unwin H, Greenlee R. Amphetamine paired with physical therapy accelerates motor recovery after stroke. Stroke 1995;26:2254-2259.

64. Walker-Batson D. Pharmacotherapy in the treatment of aphasia. In: Goldstein LB, ed. Restorative Neurology: Advances in Pharmacotherapy for Recovery after Stroke. New York: Futura Publishing, 1998:257-270.

65. Walker-Batson D, Devous Sr MD, Curtis S, Unwin DH, Greenlee RG. Response to amphetamine to facilitate recovery from aphasia subsequent to stroke. Clin Aphasiol 1990;20:137-143.

66. Walker-Batson D, Unwin H, Curtis S. Use of amphetamine in the treatment of aphasia. Restor Neurol Neurosci 1992;4:47-50.

67. Small SL. Pharmacotherapy of aphasia. A critical review. Stroke 1994;25:1282-1289.

68. Feeney DM. From laboratory to clinic: Noradrenergic enhancement of physical therapy for stroke or trauma patients. In: Freund HJ, Sabel BA and Witte OW. Advances in Neurology. 1997. Philadelphia: Lippincott-Raven Publishers, 383-394.

69. Smith P, Unwin H, Curtis S, Walker-Batson D. Negligible effects of amphetamine administration in stroke rehabilitation. Neurology. 1999;52:80-81.(Abstract).

70. Grade C, Redford B, Chrostowski J, Toussaint L, Blackwell B. Methylphenidate in early poststroke recovery: A double-blind, placebo-controlled study. Arch Phys Med Rehabil 1998;79:10471050.

71. Goldstein LB, Davis JN. Physician prescribing patterns following hospital admission for ischemic cerebrovascular disease. Neurology 1988;38:1806-1809.

72. Goldstein LB. Prescribing of potentially harmful drugs to patients admitted to hospital after head injury. J Neurol Neurosurg Psychiatry 1995;58:753-755.

73. Goldstein LB. Influence of common drugs and related factors on stroke outcome. Curr Opin Neurol 1997;10:52-57.

74. Goldstein LB. Potential effects of common drugs on stroke recovery. Arch Neurol 1999;55:454-456.

75. Goldstein LB. The Sygen in acute stroke study investigators. Common drugs may influence motor recovery after stroke. Neurology 1995;45:865-871.

76. Goldstein LB, Matchar DB, Morgenlander JC, Davis JN. Influence of drugs on the recovery of sensorimotor function after stroke. J Neurol Rehab 1990;4:137-144.

77. Graham GD, Ahmed W, Davis LE, et al. Effects of commonly prescribed medications on stroke recovery: a TOAST study analysis. Stroke 1999;30:236(Abstract).

78. Goldstein LB, Davis JN. Restorative neurology. Drugs and recovery following stroke. Stroke 1990;25:19-24.

79. Feeney DM. Mechanisms of noradrenergic modulation of physical therapy: effects on functional recovery after cortical injury. In: Goldstein LB, ed. Restorative Neurology: Advances in Pharmacotherapy for Recovery after Stroke. New York: Futura, 1998:35-78.

80. Feeney DM, Baron JC. Diaschisis. Stroke 1986;17:817-830.

81. Von Monakow C. Diaschisis. In: Pribram KH, ed. Brain and Behavior, Mood, States and Mind. Baltimore, Maryland: Penguin Book, 1969:27-36.

82. Nguyen DK, Botez MI. Diaschisis and neurobehavior. Can J Neurol Sci 1998;25:5-12.

83. Feeney DM. Pharmacologic modulation of recovery after brain injury: a reconsideration of diaschisis. J Neurol Rehab 1991;5:113-128.

84. Sutton RL, Feeney DM. Noradrenergic pharmacotherapy and functional recovery after cortical injury. In: Illis LS, ed. Neurological Rehabilitation. England: Blackwell, 1994:469480.

85. Boyeson MG, Krobert KA. Cerebellar norepinephrine infusions facilitate recovery after sensorimotor cortex injury. Brain Res Bull 1992;29:435-439.

86. Bowler JV, Costa DC, Jones BE. High resolution SPECT, small deep infarcts and diaschisis. J R Soc Med 1992;85:142-146.

87. Seil FJ. Recovery and repair issues after stroke from the scientific perspective. Curr Opin Neurol 1997;10:49-51.

88. Johansson BB. Brain plasticity and stroke rehabilitation: the Willis lecture. Stroke 2000;31:223-230.

89. Lee RG, van Donkelaar P. Mechanisms underlying functional recovery following stroke. Can J Neurol Sci 1995;22:257-263.

90. Chollet F, Weiller C. Imaging recovery of function following brain injury. Curr Opin Neurobiol 1994;4:226-230.

91. Cramer SC, Nelles G, Benson RR, et al. A functional MRI study of subjects recovered from hemiparetic stroke. Stroke 1997;28: 2518-2527.

92. Silvestrini M, Cupini LM, Placidi F, Diomedi M, Bernardi G. Bilateral hemispheric activation in the early recovery of motor function after stroke. Stroke 1998;29:1305-1310.

93. Cao Y, D'Olhaberriague L, Vikingstad EM, Levine SR, Welch KMA. Pilot study of functional MRI to assess cerebral activation of motor function after poststroke hemiparesis. Stroke 1998;29:112-122.

94. Chollet F, DiPiero V, Wise RJS, et al. The functional anatomy of motor recovery after stroke in humans: a study with positron emission tomography. Ann Neurol 1991;29:63-71.

95. Nudo RJ, Wise BM, SiFuentes F, Milliken GW. Neural substrates for the effects of rehabilitative training on motor recovery after ischemic infarct. Science 1996;272:1791-1794.

96. Stroemer RP, Kent TA, Hulsebosch CE. Enhanced neocortical neural sprouting, synaptogenesis, and behavioral recovery with D-amphetamine therapy after neocortical infarction in rats. Stroke 1998;29:2381-2395.

97. Nudo RJ, Milliken GW. Reorganization of movement representations in primary motor cortex following focal ischemic infarcts in adult squirrel monkeys. J Neurophysiol 1996;75:21442149.

98. Dobkin BH. Neurorehabilitation: greater plasticity through chemicals and practice. Neurology Network Commentary 1998;2:171-174.

99. Kozlowski DA, James DC, Schallert T. Use-dependent exaggeration of neuronal injury after unilateral sensorimotor cortex lesions. $\mathbf{J}$ Neurosci 1996;16:4776-4786.

100.Stroemer RP, Kent TA, Hulsebosch CE. Neocortical neural sprouting, synaptogensis, and behavioral recovery after neocortical infarction in rats. Stroke 1995;26:2135-2144.

101. Kawamata T, Ren J, Chan TCK, Charette M, Finklestein SP. Intracisternal osteogenic protein-1 enhances functional recovery following focal stroke. Neuroreport 1998;9:1441-1445.

102.Kawamata T, Alexis NE, Dietrich WD, Finklestein SP. Intracisternal basic fibroblast growth factor (bFGF) enhances behavioral 
recovery following focal cerebral infarction in the rat. J Cereb Blood Flow Metab 1996;16:542-547.

103.Dietrich WD, Alonso O, Busto R, Ginsberg MD. The effect of amphetamine on functional brain activation in normal and postinfarcted rat. Stroke 1990;21:147-150.

104.Gold P, Delanoy R, Merrin J. Modulation of long-term potentiation by peripherally administered amphetamine and epinephrine. Brain Res 1984;305:103-107.

105.Classen J, Liepert J, Wise SP, Hallett M, Cohen LG. Rapid plasticity of human cortical movement representation induced by practice. J Neurophysiol 1998;79:1117-1123.

106. Cohen LG, Davis B. Pharmacological enhancement of plasticity in the human motor cortex. Neurology 1999;52:A15(Abstract).

107.Loubinoux I, Boulanlouar K, Ranjeva JP, et al. Cerebral fRMI activation modulated by a single dose of the monoamines neurotransmission enhancers fluoxetine and fenozolone during hand sensorimotor tasks. Neurology 1999;52:A15(Abstract).

108.Mattay VS, Berman KF, Ostrem JL, et al. Dextroamphetamine enhances "Neural network-specific" physiological signals: a positron-emission tomography rCBF study. J Neurosci 1996;16: 4816-4822.

109.Uftring SJ, Chu D, McCandless C, et al. An fMRI study of the efffects of amphetamine on brain activity. Neuroimage 1999;(Abstract) 